\title{
The Social Fear of Female Subjectivity and Disney's Liliths
}

\author{
$1^{\text {st }}$ Ken Rahmalia Masjhur \\ Eglish Studies Program, Faculty of \\ Humanities, \\ Universitas Indonesia, \\ Depok, Indonesia \\ kennymsjhr@gmail.com
}

\author{
$2^{\text {nd }}$ Inditian Latifa* \\ Area Studies Department, Faculty of \\ Humanities, \\ Universitas Indonesia, \\ Depok, Indonesia \\ inditian@gmail.com
}

\begin{abstract}
The extant scholarly discourse on female Disney villains has often asserted the non-feminine identities of these fictional women. The female antagonists of the Disney fairy tales are generally assumed to display qualities that are believed to be too masculine. The term subjectivity is utilized in this paper as the awareness and assertion of one's agency to achieve self-led goals and lifestyles and is an attribute that is deemed by patriarchal societies to be the indicator of masculinity. However, this subjectivity is observable in each of the female Disney villains. This paper specifically examines the animated Disney movies Cinderella (1950) and Snow White and the Seven Dwarfs (1937) and compares the narratives pertaining to their antagonists with the myth of Lilith. In so doing, the paper argues that the quality of subjectivity has always been associated with femininity; however, this assertion of the self is still not considered appropriate for women. Just like Lilith, Disney's female characters display a strong sense of subjectivity but are often vilified for the affirmation of their individuality instead of being passive recipients of the vicissitudes of fate. The narratives surrounding the female antagonists of Cinderella and Snow White seem to reinforce the normative patriarchal idea that subjective females are incapable of handling the responsibilities connected to their subject status.
\end{abstract}

Keywords—Disney, villains, subjectivity, Lilith.

\section{Introduction}

The media tend to depict women who act on their opinions and desires in an unflattering light: too aggressive, too loud, or bossy are some of the many labels attached to such women. This bias against women of action can be discerned even more clearly in fiction, an arena in which the agents behind the narrative can more freely produce the characters and the story. Many of the female protagonists encountered in fiction seem to owe their personalities to the templates of fairy tale heroines who serve as passive victims [1]. At the other end of the spectrum of femininity far away from these helpless maidens is vested a less-celebrated and often-villainized model of female characters. These women are actively involved in the creation of their own narratives and in this study, they are termed subjective women. This type of female character is often conceptualized as sinister and malicious in mainstream narratives disseminated by popular media. Disney's princess movies have a long history of showcasing female protagonists modeled after fairytale maidens. Despite their childlike cheerfulness, most of Disney's classical female protagonists remain helpless and patient as they wait for their luck to change [2]. Subjectivity, or the willingness and ability to take action, is a prominent feature of classic Disney princess movies: this attribute helps audiences separate female antagonists from female protagonists. The female antagonists are always subjective while female protagonists almost never are. The persistent pattern suggests that among other traits, all female villains are coded with subjectivity, a fact that is not at all coincidental. In fact, the quality of subjectivity is one of the more prominent attributes linking the classic Disney wicked women to Lilith, one of the earliest female antagonists of human mythology.

The theme of feminine subjectivity in the female villains of Disney's Cinderella (1950) and Sleeping Beauty (1959) has not been thoroughly analyzed. However, the existence of several previously conducted studies on femininity in the Disney princess franchise must be acknowledged and noted. Disney princesses are always modeled on idealized female figures of their times. Davis's book [3] reveals the diverse types of femininity represented by the Disney princess movies. Davis believes that female characters are the most transparently constructed in animation films and that the cultural constructs that generate them are most readily observable ( $p 29$ ) in this popular genre of cultural production. England et al. [4] conducted their comparative study on the female protagonists of the Disney princess franchise vis-à-vis their male counterparts - the princes. These authors note that despite the generally non-traditional depiction of the personalities of the princes and princesses in these animated movies, the characters with whom viewers are meant to empathize are still coded to retain certain stereotypical representations of gender, especially the female protagonists ( $\mathrm{p} 555)$.

The studies mentioned above focus on different aspects of the femininity of Disney's female protagonists but they all include a shared and recurring observation: the classical Disney princesses rarely display agency. Agency in women, regardless of whether it is real or fictional, appears to be considered a double-edged sword. There are two psychological studies that most notably elucidate the idea of agency in women. Rudman and Glick's paper [5] discusses discrimination against agentic women in management settings. According to them, displays of competence and agentic traits are deemed necessary in applicants for management positions; however, organizations do not particularly welcome these qualities in women. Consequently, the possession of the very traits that are necessary for the job may exercise a negative bearing on the perceived interpersonal skills of female candidates in whom agency is often seen as the violation of a level of niceness that is seemingly only demanded in feminine individuals (p 1004). Similarly, a study published in a psychology journal observes that agency in women is generally perceived as a rebellious act against the traditionally established social gender positions, especially when it is exhibited in the presence of men. Thus, women who do display agency often find 
themselves at the receiving end of hostile sexism that attempts to correct the said inappropriate behavior [6].

Herrera et al. also compared fictional female figures with agency to the two most prominent female figures of Jewish mythology. Rousseau [7] built on this comparison in her article on procreation and its symbolic implications in the Genesis narrative, studying the differences between Lilith and Eve and positing them as opposing archetypes of femininity (p94-98).

No study has yet been conducted on the two female antagonists of Disney's Cinderella and Snow White. However, several papers have broached the general portrayal of villains. Among these, the studies conducted by Nanda [8], Guerrero [9], and Kristensen et al. [10] have discussed gender stereotypes and female representation in varied corpora including Folklore and Fairytales, Rómulo Gallegos' Doña Bárbara, and Salman Rushdie's Midnight's Children, as well as award-winning Canadian children's books.

Numerous extant studies have dissected female protagonists and the subject of female villains has been briefly touched; however, very little has been reported about the manner in which agentic females are vilified in the Disney princess franchise. Women who choose to act upon their agency and are thus subjective in the development of their narratives are called subjective women in the present paper. The Disney corpus's vilification of such subjective womenthe female characters who display behaviors that make them an active subject in their story-occurs too often to be incidental. Instead, the body of Disney's animated princess series as a whole creates a very evident evaluation of women who flaunt their subjectivity.

The present paper attempts to elucidate how these movies use the quality of subjectivity to set the female antagonists apart from the protagonist princesses, how they reinforce the negative perception of subjective women, and how these subjective women relate to the myth of Lilith.

\section{Method}

This paper's analysis of some of the female characters of the animated Disney movies Cinderella (1950) and Snow White and the Seven Dwarfs (1937) utilizes the concept of subjectivity and compares the narratives that are constructed around these characters to the myth of Lilith. The examination and comparative evaluation in this paper are intended to illuminate how these movies attempt to define an undesired or adverse archetype of femininity by focusing on the presence of subjectivity expressed by the antagonist women. The present analysis also contemplates how these antagonistic characters exercise their subjectivity and discerns the relevance of the myth of Lilith in the narratives constructed around these villainized females. The findings of this study indicate that the portrayal of the subjective female characters in these two animated films seems to support the patriarchal notion that the presence of subjectivity corrupts these women just as it tainted Lilith, Adam's first wife.

\section{Result and Discussion}

\section{A. Subjectivity in Female Characters}

Perpich [11] commented on the philosophical tradition depriving women of the status of a subject. According to this convention, subjectivity results from autonomy and reason. On the other hand, Allen [12] studied Foucault's and Arendt's treatises on power, subjectivity, and agency and described subjectivity to be a precondition for agency. This understanding stems from the awareness that an individual's capacity to act can only emanate from the person's capacity to think and to decide, an ability owned only by a thinking subject. It is inferred by this interpretation that subjectivity refers to a person's fulfillment of the subject status as observable through displays of decision-making and actiontaking. The subjective women who are studied in this paper represent female characters whose decisions and actions actively shape the development of the concerned narrative, allowing them to become the subjects of sentences of their own making and to act on their own cognizance.

Disney's animated movies Cinderella (1950) and Snow White and the Seven Dwarfs (1937) both seem to agree with the patriarchal idea that women should not be subjective. Lady Tremaine and the Evil Queen are in positions that provide them to wield power over themselves as well as others. Conversely, the protagonists Cinderella and Snow White do not occupy positions that empower them in any way. Foucault's interpretation of power prescribes it as a condition for individual subjectivity [12]. Thus, the positions of the antagonist characters accord them with subject status, albeit to different extents. The subjectivity of these women is then exercised when these characters establish a goal they desire to achieve. In both movies, the principal objectives of the antagonists are centered around the extreme value they place on beauty. Although it is common practice in such movies to place great value on beauty, the pursuit of beauty itself - and the benefits that emanate from it - seem to be particularly reprehensible. In these narratives, beauty is an attribute "gifted" by fate to characters with good hearts. Any personal efforts to empower oneself through the acquisition of beauty or the benefits that result from it is regarded as a rebellion against fate's design. The stance of such movies on women with subjectivity is visible in the manner of the portrayal of women who intend to choose their desired path and act on their choices. The movies condemn these women who have subjectivity as villains; on the other hand, women without subjectivity are eventually rewarded for their perseverant passivity.

In Cinderella (1950), Lady Tremaine's use of subjectivity to attain her goals make her rebel against her established fate, which corrupts her character and labels her a villain. Cinderella, who remains passive about her lot in life, is ultimately rewarded and is depicted as innocent and pure.

Lady Tremaine, Cinderella's stepmother, first appears in the movie not long after she marries into wealth as a widowed mother of two. However, the absence of warmth and affection between Lady Tremaine and her new family is also underscored to imply that she is the kind of person who uses the institution of marriage to acquire wealth. To set the scene, the newly married Lady Tremaine is showcased in a dark room on the second floor with her two daughters, watching Cinderella - the protagonist - and her father play with their animals outside. The gloom of the room, the dark shadows over her face, and the angle from which she watches the pair serve as tools through which the illustrators of the animated movie establish her character as distant, manipulative, and malicious. On the other hand, the young Cinderella is depicted 
in the garden in the same scene, blissfully unaware and uninvolved in the formation of her own fate. The fact that Cinderella stands directly under the sun while Lady Tremaine is obscured from light within the confines of a dark room is also significant: the sun is a common reference to the light or to the grace of God and/or Jesus. Throughout history, references have been made to Jesus using the symbol of the sun [13]. Therefore, being touched by light parallels being touched by God, or Goodness.

Like Lady Tremaine, The Evil Queen in Snow White and the Seven Dwarfs (1937) is a ruling Queen without a King. She enters the narrative with a backstory that already taints her character with subjectivity. However, she is then depicted exercising her subjectivity once more when she wants to alter fate by making herself the most beautiful woman in the kingdom. Of course, her stepdaughter Snow White, whom fate has made naturally beautiful, does nothing to alter her circumstances, becomes a victim, and remains innocent and pure. The scene that introduces the audience to the Queen and Snow White first shows the Queen in a dimly lit room where she performs what is obviously a ritual with a magical artifact. In this scene, the Queen is shown summoning a being in the mirror: "Slave in the magic mirror, come from the farthest space. Through the wind and darkness, I summon thee! Speak! Let me see thy face." [14].

This address of "slave" and the loud commands the Queen issues to this being reinforce her status as someone who wields power, not only over her kingdom but also over the magical beings. The spirit that dwells in the mirror then appears behind a smokescreen after a long burst of flames. The presence of fire and smoke is an immediately recognizable reference to hell. This scene thus strengthens the unholiness of the Queen's character; she is the one with power over a hellish spirit. Despite the simplicity of the ritual she performs, this scene also serves to build distrust of the Queen's character, cementing the audience's perception that she is a wicked witch who uses magic to get her own way.

The ritual itself and the imagery that surrounds it leave no room for speculation that the woman's intentions could be benevolent. To ensure that no one in the audience receives the wrong message, The Evil Queen is also pictured in a purple robe. As a color, purple is associated with mysticism, royalty, power, and ambition. As she continues with her ritual, the audience is also able to determine that the unfulfilled ambition that causes her to rebel against her fate is her desire to possess "beauty above all others."

The scene then switches to Snow White, clad in rags, cleaning the steps of the castle's gardens. As is the case with Cinderella in Lady Tremaine's introduction scene, Snow White is shown surrounded by nature in full sunlight. Therefore, in both Cinderella (1950) and Snow White and the Seven Dwarfs (1937), the locations of the antagonist and protagonist emphasize their divergent positions, capabilities, and their likelihood of being subjective. After Snow White meets the prince, the camera shifts back to the room on the higher floor occupied by the Queen. The shot lingers on the Queen as she maliciously watches the two youngsters from behind stained-glass windows, with railings separating her from the outside. This shot reinforces the differences between Snow White and her stepmother in metaphorical standing; it also underscores how far removed the Queen is from the experiences and symbols that permeate the spaces outside her room: innocence, love, light, and all that is good.

\section{B. The Abuse of Power by Subjective Female Characters.}

The movies Cinderella (1950) and Snow White and the Seven Dwarfs (1937) both seem to agree with the patriarchal notion that women are not suited to the quality of subjectivity. The long-held traditional beliefs that recognize subjectivity as the presence of reason and autonomy also view women as incapable of possessing either. This philosophical perspective is constantly presented in the characterization of the two female villains, Lady Tremaine and the Evil Queen. Both women are in positions that accord them power over themselves as well as others. On the other hand, both Cinderella and Snow White are completely unempowered protagonists. Foucault's understanding of power and its positioning as a condition for individual subjectivity is cited again in this context. The argument against the subjectivity of these female characters is most visible by the way they always seem to only make decisions that are unfair to say the least. The multiple instances of these characters exercising their power repeatedly reinforce the notion that women incapable of appropriately utilizing their autonomy or reason [11].

Lady Tremaine abuses her power every time she obtains the opportunity to be subjective. The first time Lady Tremaine can become both an action-taker and decision-maker in the movie Cinderella (1950) occurs after Cinderella's father dies. Cinderella's father's death leaves Lady Tremaine in the position of power as the lady of the house. Instead of decisionmaking that is driven by long-term planning or collective need, Lady Tremaine is shown to be motivated by petty cruelty and by her bitter jealousy of Cinderella's beauty. Seemingly incapable of governing her own envious nature, she wrongfully forces Cinderella out of her position of the house owner's daughter and forces her to take the status of a lowly maid. Lady Tremaine's abuse of authority is first exhibited when she denies Cinderella the comfort and privilege of her father's wealth and is, rather, "grimly determined to forward the interests of her own two awkward daughters." Another scene of particular importance follows when Lady Tremaine summons Cinderella. As Cinderella enters the room, Lady Tremaine is portrayed sitting on her bed under luxurious drapery. Acting as judge, she punishes Cinderella one chore after another. Visually, this scene bears a strong resemblance to the image of an unjust King with a troublesome subject. Lady Tremaine's bed and drapery are visual reminders of her power-position. She is "enthroned" while Cinderella stands at her feet as an accused subject trying and failing to plead her case. This scene strengthens, once more, the previously mentioned belief that women are unfit for subjectivity because they are incapable of exercising reason. In this instance, Lady Tremaine is not only portrayed as a character incapable of reason; she is also shown to be immune to attempts by others to appeal to reason. She acts solely for self-fulfillment, punishing a hapless and helpless child for her own feelings of jealousy.

Similarly, the Evil Queen also represents a character who abuses her powers for petty motives. Throughout the movie, the Evil Queen repeatedly proves herself a slave to her own emotions, despite her position as a ruler. The scale of her authority serves only to increase the magnitude of the effects of her actions. While Lady Tremaine acts as an unjust ruler within the confines of her own house, the Evil Queen is an 
unjust ruler of a real castle and kingdom who is particularly unfair to her stepdaughter. Unlike Lady Tremaine, however, the Queen's subjectivity is not merely derived from the power of her position but also from her mastery of the infernal and taboo witchcraft. Instead of using her considerable powers for the benefit of her kingdom or even to serve her political needs as the queen, the Evil Queen's motive to act appears just as petty as Lady Tremaine's - fear. The Queen "feared that some day Snow White's beauty would surpass her own." Thus, she first abuses her power as both a parent and the queen of the kingdom: she "dressed the little princess in rags and forced her to work as the Scullery Maid." The portrayal of the Evil Queen as someone who allows her fear to direct her actions is another demonstration of a female character's incapacity of using reason for decision-making, and proof that she is instead driven by emotions. In another scene, the Evil Queen also fully exercises her subjectivity, enabled by her power as the Queen: she commands a huntsman to murder Snow White. In this scene, the Queen commits blatant abuse of her authority as she commissions the perpetration of a heinous crime on an innocent girl simply to allay her fear. Later, she is again seen using her powers for petty ends: this time, as a skilled practitioner of witchcraft, she transforms herself, creates a poisoned apple, and deceives Snow White. It is also noteworthy that despite her exalted position, the Evil Queen is never shown to perform any of her royal duties.

These findings about Lady Tremaine and the Evil Queen support the postulation that the two studied movies serve to cement the notion that women are not suited to subjectivity. The Evil Queen is incapable of being a good ruler; she is also unable to put her general subjectivity to good use. In all three instances that she is portrayed as exercising her subjectivity, her actions are dictated by her emotions instead of reason or by the concern for the general welfare of her kingdom. These characters live in a world where people are valued by their beauty. The two antagonists are themselves victims of this belief: they think that beauty is a person's most prized possession. Lady Tremaine understands that beauty is a currency she does not own; the Evil Queen attempts to protect her status presumably as the kingdom's alpha female by ensuring that her beauty exceeds the attractiveness of all others in her region. The value placed in beauty, then, becomes a double-edged sword as it motivates Lady Tremaine and the Evil Queen into acting. The beauty of the protagonists is also highly regarded, partly for its internal manifestation as the desirable traits of the patriarchal construct of femininity. Ironically, the struggle for beauty is, in itself, seen as a petty and despicable act.

\section{Lilith in Lady Tremaine and the Evil Queen}

This paper asserts that Lady Tremaine and the Evil Queen are metaphorical descendants of the archetype of Lilith, one of the earliest mythical females to subjectively action her own narrative. Multiple narrative and personality-related aspects of the characterization of these female antagonists seem to be coded with Lilith's mythical DNA. While it is difficult to conjecture the origins of the tradition of comparing bad and good women, it can be asserted with certainty that this convention harks back at least to $3000 \mathrm{BCE}$ [15], to the juxtaposition of Lilith against Eve, the first two women to be created according to Hebrew mythology. Lilith, Lady Tremaine, and the Queen all very notably possess subjectivity despite the norms that prevailed in their times. Additionally, other factors appear to suggest that the resemblance between these three figures is not completely unintentional and that Lilith shapes the image of the other two.

Lady Tremaine's resemblance to Lilith may be witnessed both in the narrative and the visual aspects of the movie, which alludes to several aspects of the myth of Lilith. The narrative about both the figures paints them as manipulative and describes how they utilize traditionally feminine roles to advance their own ends. The visual aspects become evident in allusions made in certain scenes to the story of Lilith.

Manipulation is perceived as especially threatening in women. Lady Tremaine and Lilith both lower the guards of their victims before causing injury; this trait is understandably adjudged as more offensive than an outright attack. Lady Tremaine allows Cinderella to go to the ball on the condition that she completes all her chores and finds something suitable to wear. In so saying, she gives Cinderella hope, secure in the knowledge that she can just easily crush it later. Similarly, Lilith assumes the figure of a beautiful virgin to lower the guards of men she seduces for seeds [16].

The utilization of traditionally identified and labeled feminine roles to achieve personal ambitions is another trait shared by Lady Tremaine and Lilith. First introduced as a widow with two daughters, Lady Tremaine marries Cinderella's father for wealth. Cinderella's father wanted to marry Lady Tremaine so she could fill his late wife's shoes. Instead, Lady Tremaine uses the opportunity of her beneficial marriage to advance her own interests and those of her daughters. Lilith, similarly, is notorious for copulating with unsuspecting men, taking their seeds, and birthing children to generate a legion of her own that she could use to advance her own interests [16]. Both figures, therefore, take on traditionally established womanly duties of being wives and mothers and subvert those patriarchal constructs to benefit their own agenda. This tactic is also later extended by Lady Tremaine to her daughters, whom she tries to get married into wealth to fulfill her ambitions. This action also bears resemblance to Lilith's use of seduction to acquire whatever she desires.

Visually, Lady Tremaine is also quite boldly likened to Lilith. In a scene near the beginning of the film, Lady Tremaine summons Cinderella thinking that the latter had pulled a prank on Anastasia. The shot reveals Lady Tremaine sitting in bed under luxurious purple drapes. Her features are concealed by the shadows. She strokes her companion, Lucifer the cat, who is seated on her lap. This setting harks back to a famous Talmudic myth that describes Lilith as living in a dark cave over the red seas. Multiple traditions also add that she lived with her lover and companion, the archangel Samael [16]. Because of his job of seducing and misleading humankind, it is not uncommon for Samael to be mistaken or associated with Lucifer (TV Show Lucifer, 2016-present). This similarity is especially resonant with cultures familiar with Judeo-Christian myth.

The resemblance between the Evil Queen and Lilith is not as obvious as Lady Tremaine's characterization. The Queen's character is nonetheless inspired to some extent by the mythical figure. There are several references to Lilith in the Evil Queen's case, especially in her presentation to the audience as a woman who knows dark magic, can disguise herself easily and occupies a position of power. The two 
characters also notoriously use their considerably evident beauty to improve their positions and achieve their ends.

The two figures are both acting Queens who rule over kingdoms. The Evil Queen's power comes from her position as the current ruler. It is this authority that enables her to command the huntsman to murder Snow White. Her abuse of authority is different, but not completely unlike Lilith's misuse of her authority. According to the myth, Lilith first attains her authority by making herself the leader of a band of demon children she creates. Later scriptures claim that she then uses these spawned children to achieve her own objectives and becomes the queen of Zemargard and Sheba [16].

The two figures also share their command of the art of dark magic. The Evil Queen summons a strange being she refers to as her slave in the mirror to answer her questions and uses books on witchcraft to aid her nefarious efforts. Evidently, the Queen is no stranger to the use of dark magic to achieve her desired ends. Similarly, Lilith is known to practice the ways of harming women and children, and stealing semen off unsuspecting men; her ways are incomprehensible to the logical mind. Her fearsome dark power caused men to recite a special prayer during intercourse to fend off Lilith's ability to sneak into their beds to steal their seed and create demon children [16].

Lilith and the Queen are also similar in their use trickery and disguise to get what they want. The only difference between them can be asserted in the fact that Lilith assumes the appearance of an unsuspecting beautiful virgin to get the seed she wants while the Evil Queen assumes the appearance of an ugly old woman. Both use their disguise to lower the guards of their victims. In Lilith's case, the appearance of an unsuspecting virgin enables her to seduce men and take advantage of their intentions to take advantage of her [16]. The Queen assumes the appearance of an older woman to gain Snow White's sympathy so she accepts her gift of the poisoned apple.

Beauty means a lot more than mere aesthetics to these two women; it is a tool as well as the parameter of their success. The Evil Queen appears to perceive her alpha female status as resulting from her unparalleled beauty. In this sense, the Evil Queen perceives her beauty as a tool with which she can pursue her ambitions: her power is linked in her mind directly to her beauty. Similarly, besides stealing seeds from the beds of unsuspecting couples, Lilith used her beauty and her tactics of seduction as tools with which she could fool men into giving her the seeds with which she could create hundreds of demon children to build her legions.

\section{Conclusion}

Numerous aspects remain unconsidered in this paper with regard to the characterization of the female villains of Disney's classical princess series of animated films. Future researchers should also probe the manner in which the creators of these films perceive femininity. The present paper attempted to establish three points. First, the two studied movies subscribe to the patriarchal idea that women are not fit for subjectivity. Second, the perceived incompatibility between the traits of a subjective personality and the ideal notion of femininity is made apparent by the way subjectivity is used in these movies as the defining trait that distinguishes the "bad" and "good" feminine characters. Finally, the female antagonists of the two studied films are, to a certain extent, modeled on the personality and story of Lilith, the first woman of Hebrew mythology.

The overall media narrative against subjective women remains predominant despite notable transformations that may be observed in some recent depictions of subjective female characters. As humanity progresses, it is crucial to remember the historical cultural productions that shape and reinforce the prevailing social narratives, outdated as they may seem. Remembering how things were in the past will enable humanity to move forward to the future with newer, better, and more equitable societal constructs and narratives.

\section{References}

[1] Lieberman, M. (1972). "Some Day My Prince Will Come": Female Acculturation through the Fairy Tale. College English, 34(3), 383-395. doi: $10.2307 / 375142$

[2] Bell, E., Haas, L., \& Sells, L. (Eds.). (1995). From mouse to mermaid: The politics of film, gender, and culture. Indiana University Press.

[3] Davis, A. M. (2007). Good girls and wicked witches: changing representations of women in Disney's feature animation, 1937-2001. Indiana University Press.

[4] England, D. E., Descartes, L., \& Collier-Meek, M. A. (2011). Gender role portrayal and the Disney princesses. Sex roles, 64(7-8), 555-567.

[5] Rudman, L. A., \& Glick, P. (2001). Prescriptive gender stereotypes and backlash toward agentic women. Journal of social issues, 57(4), 743762

[6] Herrera, M. C., Expósito, F., \& Moya, M. (2012). Negative reactions of men to the loss of power in gender relations: Lilith vs. Eve. The European Journal of Psychology Applied to Legal Context, 4(1), 17.

[7] Rousseau, V. (2005). Eve and Lilith: Two Female Types of Procreation. Diogenes, 52(4), 94-98.

[8] Nanda, S. (2014). The portrayal of women in the fairy tales. The International Journal of Social Sciences and Humanities Invention, $1(4), 246-250$

[9] Guerrero, B. (2016). Representing Modern Female Villain: On Feminine Evil, Perverse Nationhood, and Opposition in Rómulo Gallegos' Doña Bárbara and Salman Rushdie's Midnight's Children.

[10] Kristensen, E. (2016). Villains, Heroes, and Parents.

[11] Perpich, D. (2003). Subjectivity and sexual difference: New figures of the feminine in Irigaray and Cavarero. Continental Philosophy Review, $36(4), 391-413$

[12] Allen, A. (2002). Power, subjectivity, and agency: Between Arendt and Foucault. International journal of philosophical studies, 10(2), 131149

[13] Murdock, D. M. (2011). Jesus as the Sun throughout History. Stellar House Publishing.

[14] Disney, W. (Producer), Hand, D., Cottrell, W., Jackson, W., Morey, L., Pearce, P., \& Sharpsteen, B. (Director). (1937). Snow White and the Seven Dwarfs [Motion Picture]. United States: Walt Disney.

[15] Hammer, R. J. (n.d.). Lilith: Lady Flying in Darkness. My Jewish Learning. Retreived July 16, 2019 from https://www.myjewishlearning.com/article/lilith-lady-flying-indarkness/

[16] Patai, R. (1990). The hebrew goddess. Wayne State University Press

[17] Disney, W. \& Bailey, A. (Producer), Geronimi, C., Jackson, W., \& Luske, H. (Director). (1950). Cinderella [Motion Picture]. United States: Walt Disney. 